\title{
La perspectiva relacional de la comunicación en los procesos de e-Salud en Brasil: el proyecto Maluco Beleza
}

\author{
Nathália Silva Fontana Rosa \\ Universidad Autónoma de Barcelona
}

\section{Palabras clave \\ Comunicación y salud e-Salud participación perspectiva relacional}

\begin{abstract}
Resumen
En el campo de la comunicación y salud coexiste una disputa de modelos y concepciones, marcado actualmente por el proceso de convergencia de las Tecnologías de la Información y de la Comunicación (TIC) en el ámbito, conocido por e-Salud. El objetivo del presente artículo es comprender tales procesos con la intención de analizar la participación a la luz de una perspectiva relacional de la comunicación, que la entiende como un proceso de producción social de sentidos en el marco de un contexto social y cultural.

Tras realizar entrevistas y grupos focales en la "Radio Maluco Beleza", programa de radio online protagonizado por usuarios de la red de salud mental, se destaca que el uso de las TIC en salud, aplicada desde una perspectiva relacional, puede ampliar y profundizar las posibilidades de expresión y promover la participación. El análisis de los usuarios acerca de los hechos del cotidiano, incluso su enfermedad, es una producción de saberes que no están contempladas en el espacio hegemónico de los medios de comunicación, los cuales privilegian el discurso tradicionalmente autorizados, tales como instituciones, servicios y equipos de salud. La comunicación para la salud desde esta mirada, fomenta la participación y reconoce la existencia de una polifonía social, con la capacidad de acoger y ampliar las muchas voces que contienen una multiplicidad de posibles significados para la salud y la vida
\end{abstract}




\section{Relational communication perspective on the processes of e- Health in Brazil: Maluco Beleza Project}

\author{
Key words \\ health communication \\ ehealth \\ participation \\ relational perspective
}

\begin{abstract}
Health communication in Brazil is a field where coexists a dispute of models and concepts, currently marked by the convergence of Information Technology and Communication (ICT), known for ehealth. The aim of this article is to understand these processes with the intention of analyze participatory approaches in light of a relational perspective of communication, understood as a process of social production of meaning in the context of a social and cultural process.
\end{abstract}

After stands conduct interviews and focus groups in the "Radio Maluco Beleza", online radio program starring network users mental health, the use of ICT in health, applied from a relational perspective, can broaden and deepen possibilities of expression and promote participation. The analysis of users about the facts of daily life, even his illness, is a production of knowledge that are not covered by the hegemonic space of the media, which favor the traditionally speech such as institutions, services and equipment health. The health communication from this perspective, encourages participation and recognizes the existence of a social polyphony, with the ability to receive and expand the many voices that contain a multiplicity of possible meanings for health and life.

\section{Cómo citar el artículo}

Silva Fontana Rosa, N. (2015). La perspectiva relacional de la comunicación en los procesos de e-Salud en Brasil: el proyecto Maluco Beleza. Revista de Comunicación y Salud, Vol. 5, pp. 55-67.

DOI: http://doi.org/10.35669/revistadecomunicacionysalud.2015.5.55-67 


\section{Introducción}

Los procesos comunicativos en el ámbito de la salud en Brasil comprenden un campo complejo, influenciado por prácticas y teorías que a lo largo del tiempo son replanteadas por los actores en sus acciones. El modelo difusionista, muy utilizado a partir de la década de los 50 con las teorías de la modernización, sigue influenciando los procesos comunicativos en la salud. Esa perspectiva considera los problemas de salud desde un carácter meramente individual y, de esta manera, objeto de una intervención de cambios de comportamientos a través de informaciones adecuadas, siguiendo un esquema lineal de la comunicación desde un emisor con conocimientos hacia un receptor que tiene que cambiar sus comportamientos.

Sin embargo, propuestas más participativas de la comunicación disputan ese territorio, donde la propia concepción de la salud se desplaza para una visión más amplia y múltiple. La comunicación, bajo esa mirada, alcanza procesos más horizontales y dialógicos, considerando las especificidades culturales y sociales, en especial, a partir de una perspectiva relacional de la comunicación, que la define como el proceso de producción social de sentidos en el marco de un contexto social y cultural (Díaz y Uranga, 2011).

En este enfoque, que interesa al presente artículo, los diferentes contextos - históricos, económicos, políticos, institucionales, y también textuales, intertextuales, existenciales y situacionales juegan un papel decisivo en los procesos de comunicación (Araújo y Cardoso, 2007). El proceso de comunicación no se limita a la transmisión de contenidos predeterminados, se entiende desde una perspectiva de producción de sentidos, en la cual se toma en consideración no solamente los signos y los códigos empleados en un discurso, sino más bien la propia realidad (referente) de la comunicación (Pintos, 2001), es decir, el contexto en el cual están actuando los sujetos que participan en el proceso comunicativo. Como propone Bakhtin (1988, 1992, apud Araújo y Cardoso, 2007), cada palabra tiene múltiplos significados y está habitada por diferentes voces, lo que configura una polifonía de voces que expresan diferentes sentidos, condiciones sociales, económicas, disputas de poder, etc.

Esos modelos siguen presentes y en disputa en el contexto de la e-Salud, proceso de convergencia de las Tecnologías de la Información y de la Comunicación (TIC) en el ámbito de la salud ${ }^{1}$. El desarrollo de las aplicaciones de las TIC a todos los sujetos que conforman el sector de la salud -instituciones, trabajadores y ciudadanía-, tanto en las actividades relacionadas con la atención, la gestión y la educación en salud, como en el uso y apropiación de las herramientas de comunicación por la sociedad, si bien abren un nuevo marco para el estudio e implementación de la comunicación en el campo de la salud, posibilitan también la manutención de la lógica difusionista y la no participación de las personas.

1

La CEPAL (2003) entiende que las TIC se definen como sistemas tecnológicos mediante los que se recibe, manipula y procesa información, y que de esta manera facilitan la comunicación entre los interlocutores, más allá de informática y computadoras, puesto que funcionan en conexión mediante una red, y que tampoco son solamente divulgación de información, ya que permiten una comunicación interactiva. Salvat y Serrano (2011) comprenden las TIC como la integración multimedia de viejas tecnologías de la información (radio, teléfono, cine, prensa y TV) y su digitalización a partir del desarrollo de la informática. En este sentido explican que lo digital supone un cambio, ya que el nuevo sistema tecnológico que configura Internet ha sido capaz de crear una instancia nueva, un universo virtual, el ciberespacio. 
La política nacional de salud brasileña prevé un grado mayor de participación ciudadana, con el objetivo de mejorar la atención y generar una autonomía del individuo y de los colectivos en las decisiones sobre su vida. La "Política Nacional de Gestión Estratégica y Participativa en el SUS: ParticipaSUS", por ejemplo, defiende que la construcción del modelo de atención a la salud sea fundamentado en las necesidades y demandas de la población por acciones y servicios de promoción, protección y recuperación de la salud (Brasil, 2005).

Haciendo un paralelo con los procesos comunicativos en el ámbito, la política establece que esta tarea exige el esfuerzo de desencadenar acciones que operen en el sentido de ampliar la vocalización de las necesidades y de los deseos de la población y la escucha de los profesionales y de los servicios, para que el acogimiento y el cuidado tengan significado para ambos. Presupone, por lo tanto, la ampliación de espacios públicos y colectivos para el ejercicio del diálogo.

Partiendo de esta base, el objetivo del estudio es comprender el campo de la comunicación y salud en Brasil a partir del debate de las aplicaciones de las TIC, con la intención de analizar la participación a la luz de una perspectiva relacional de la comunicación, presentado en el contexto del estudio de caso "Rádio Maluco Beleza", programa de radio online protagonizados por los usuarios de la Red de Salud Mental del Servicio de Salud Dr. Cândido Fereira, y otros miembros de la comunidad del municipio de Campinas (Estado de São Paulo) ${ }^{2}$. La radio es parte del proyecto "Maluco Beleza"3, que desde su creación en 2002, tiene el objetivo de reducir el prejuicio sobre la locura, revelando nuevas posibilidades para el tratamiento y la convivencia con las diferencias y con los diferentes.

\section{El diseño metodológico: la construcción del sentido de la investigación}

Para alcanzar acercarse a la realidad de las interacciones que el uso de las TIC generan en el campo de la salud, se ha optado por emprender un estudio de caso en la "Radio Maluco Beleza", un espacio capaz de captar la diversidad de los procesos comunicativos en el campo, considerando que no existen prácticas homogéneas de cuidado en salud. Con tal abordaje, "se estudia la salud no sólo como el resultado de determinadas intervenciones, sino explorándola desde el punto de vista de la concepción cultural y simbólica que la población tiene de la misma" (Conde y Pérez Andrés, 1995: 146-147).

\section{2}

El Servicio de Salud Dr. Cándido Ferreira (SSCF), situado en el municipio de Campinas (São Paulo - Brasil), es una organización caritativa fundada 24 de abril de 1924. Es una referencia en el tratamiento de la salud mental en Brasil desde 1993 por la Organización Mundial de la Salud (OMS). El objetivo principal de la institución es la desinstitucionalización, la participación social de los usuarios y el respeto al derecho de la coexistencia de los diferentes. Hoy día, Cándido Ferreira ofrece servicio a más de mil usuarios por mes.

3

Una de las acciones iniciales fue el programa de radio, resultado de una colaboración entre el Servicio de Salud y la Radio Educativa del municipio, que transmite mensualmente el programa producido por los participantes, con una hora de duración. Actualmente, la radio online, en la página web "Maluco Beleza" (www.radiomalucobeleza.org.br), transmite programas presentados y producidos por los usuarios, los trabajadores y las familias de la Red de Salud Mental y otras iniciativas sociales de Campinas. 
Partiendo del presupuesto de que para lograr resultados positivos en las políticas de salud es necesario ampliar y calificar la escucha de las demandas de salud de los sujetos, movimiento generado por la participación de los mismos, se ha optado por analizar un proceso en el cual se utilizan las herramientas de la comunicación para propiciar un incremento en la posibilidad de participación y expresión de los sujetos, en un espacio comunicativo creado por los propios usuarios en una institución de salud mental. De esa manera, proporcionaron elementos para discutir la participación a partir de uso de las TIC en el campo de la comunicación y salud a la luz de una perspectiva relacional de la comunicación.

Se han recogido los datos a través de entrevistas semiestructuradas y grupo focal, además del análisis de bibliografía y de datos secundarios, de acuerdo con el carácter emergente y multi-método del estudio de caso. En total, fueron realizadas cuatro entrevistas individuales - un comunicador del proyecto (C.1.I), un psicólogo de la red de salud mental del municipio (P.1.I) y dos locutores ${ }^{4}$ de la radio (L.1.I y L.2.I) - y un grupo focal (GF) con nueve locutores (L) de la radio. Fueron tomados como colaboradores aquellos que participan o bien conozcan el programa de la radio en profundidad, con el objetivo de comprender la trayectoria de los mismos en relación a la participación en el proceso comunicativo llevado a cabo por la institución. Respetando la lengua original de los entrevistados, los recortes discursivos de las entrevistas se presentan en portugués.

Siguiendo tal perspectiva, la información recogida a partir del estudio en el campo ha sido analizada a partir de la acción de triangulación hermenéutica, que consiste en la acción de reunión y cruce de toda la información pertinente al objeto de estudio surgida en una investigación, ya sea mediante la recopilación de información en el trabajo de campo o mediante la revisión bibliográfica; y donde es el investigador quién le otorga significado a los resultados de su investigación (Cisterna, 2005), sin determinar de antemano técnicas de tratamiento de datos, sino su autocomprensión (Minayo, 1992).

\section{Resultados y Discusión: producción de sentidos en el análisis de la "Radio Maluco Beleza"}

Antes de presentar los resultados, y como fundamental para la emprender la discusión establecida, importante destacar que la perspectiva relacional, en lugar del esquema lineal de emisor-mensaje-estímulo-receptor-respuesta, contempla un circuito constituido por las instancias de producción, circulación y reconocimiento, a partir de las cuales las entrevistas y los datos fueron analizados.

Estas instancias no son consideradas estáticas, sino que se enmarcan en un conjunto de condiciones de tiempo, espacio y relaciones sociales que son dinámicas. En suma, condiciones de producción, circulación y reconocimiento que configuran, en la trama discursiva, una determinada realidad socio-cultural. (Díaz, 2011: 39)

Así, la producción, la circulación y el reconocimiento son conceptos que están ellos mismos enmarcados en una disputa de sentidos y del poder en la sociedad: cómo

4

Se ha optado llamar a los participantes de la radio de locutores, respetando la manera como describen a sí mismos. Son o fueron usuarios de la red de salud mental, como también miembros de la comunidad en general. 
hacer comunicación y quiénes son los que tienen ese derecho (producción); dónde el material comunicativo debe circular, en especial donde no debe llegar (circulación) y desde qué instancias - instituciones de salud, médicos, profesionales de la salud, etc - la comunicación en salud es considerada legitima (reconocimiento).

De esa manera, en tal perspectiva, la comunicación, como un proceso de producción de los sentidos sociales, funciona como un dispositivo de activación de un circuito productivo de los sentidos, que ayudarán a construir las categorías que se presentan a continuación:

\section{El uso de las TIC: un dispositivo de activación de un circuito de producción y expresión de los sentidos}

El uso de las TIC, si bien apuntan a una participación más activa de las personas en comunicación, por si no logra cambios en los procesos comunicativos. Eso porque las modalidades de comunicación vinculadas a su práctica se encuentran susceptibles a la coerción de otras órdenes que influyen en la sociedad, tales como: estrategias que buscan la manutención de una legitimidad de aquellos que pueden hablar sobre la salud - como las instituciones, los médicos - y también qué decir y cómo hacerlo - el proceso dicotómico de salud/enfermedad, cuyas estrategias de enfrentamiento se basan en las teorías comportamentales (con la información adecuada se logra un cambio en el comportamiento de las personas).

Así, es necesario que sean las TIC dispositivos de participación, en un proceso que esté él mismo atravesado por un cambio en la manera de pensar y hacer la comunicación. Fue posible observar que las distintas actividades sugeridas en la institución -cursos, eventos, comunicación- reflejan una ampliación de las ofertas para los usuarios de la red de salud mental, como dispositivo de activación de un circuito de producción y expresión de los sentidos.

Se destaca en las entrevistas que el uso de las TIC, a través de la radio online, ha ampliado los espacios discursivos de los participantes, como también, que alcanzaron un mayor grado de libertad en la producción de los programas, de los temas trabajados, entre otros, permitiendo a todos los participantes un cambio en la matriz de circulación y producción de la comunicación, como destacamos de lo que dice la comunicadora del proyecto:

"A rádio online vem trazer essa liberdade de falar o que quiser de fato (...). A gente ajuda quando eles sentem necessidade de algo, então conversam e dialogam para aprimorar, mudar, colocar quadros, etc. Eles ficam mais na produção de fato: escolhem os entrevistados, criação do nome, cada um cria 0 seu, escolhem o tipo de programa, uns querem de música, outros de entrevistas, outro quer misto".(C.1.I)

Además, los participantes de la radio entienden que con la radio online, su capacidad de conexiones y creación de red ha sido ampliada. Tal como nos cuenta uno de los locutores en el grupo focal, con la radio en internet no solo toda la gente les puede oír, sino que también pueden conectarse a través de las redes sociales, profundizando el propio circuito de producción, circulación y expresión:

"Uma coisa que eu acho interessante porque ao mesmo tempo que eu estou aqui, a minha voz está lá fora do país. Para mim isso é muito interessante, a gente ter a capacidade através da rádio online de mostrar o conteúdo que a 
gente tem, não só para quem está no Brasil, mas para quem está fora também. Esse mundo virtual veio para melhorar o nosso sistema mundial".(L.8.GF)

\section{Producción de otros sentidos sociales: el hacer comunicación, los diagnósticos, etc.}

Por lo anterior, se percibe que el proceso comunicativo establecido en este espacio posibilita la producción de otros sentidos, es decir, poder hablar y expresarse permite a las personas replantear ideas o conceptos muy arraigados tales como el hacer comunicación, la locura, los diagnósticos, la enfermedad, entre otros. Partimos de la idea de que los sentidos tienen el atributo de la pluralidad y del dinamismo, y designa algo en construcción permanente, es decir, los sentidos son producidos en situación, en la acción comunicativa. Eso está relacionado con la disputa por el "poder de hacer ver y hacer creer" (Araújo y Cardoso, 2007), estructurante de las relaciones y de la práctica comunicativa en las disputas de los sentidos en los procesos comunicativos: qué las personas tienen que saber, las conductas saludables, las necesidades, etc.

La comunicadora apunta dos movimientos interesantes en su entrevista: un movimiento particular, en el cual ella misma ha resignificado el tema de la locura, considerado hasta entonces un tabú en su vida, el cual generaba miedo y angustia. También, apunta para un intenso movimiento de los propios participantes, que cambian su lugar a partir de la participación en la radio: salen de una posición única, impuesta por la limitación del diagnóstico de la locura, para un lugar múltiple de producción como comunicadores, como militantes de la salud mental, se presentan como periodistas en eventos, son invitados a ser conferencistas, son músicos, cantantes, entre otros.

"Aqui os diagnósticos se dissolvem, o que é fantástico, porque todo mundo aqui é tratado como igual, ele também é um comunicador, ele também é um locutor, ele também é um jornalista, fazemos a mesma coisa, produzimos a mesma coisa, produzimos juntos". (C.1.I)

Los participantes de la radio, como podemos observar de los que nos cuenta uno de los locutores en el grupo focal, también comparten de esa misma visión. Hablan de un lugar mucho más amplio que la locura: se presentan como comunicadores, que tienen también una característica de una enfermedad mental, pero que no determina la manera como interaccionan en la vida.

"Aqui contempla outras dimensões, as relações, as ideias, e uma coisa muito importante: como mudou a saúde mental. Antes, a gente não tinha direito a voz. Hoje, a nossa voz tem muitos direitos. Quando você ia imaginar um paciente falando na rádio? A voz do paciente na saúde mental era uma voz muda. Ele não tinha direitos". (L.2.GF)

Así, la perspectiva relacional, como una otra práctica comunicativa, tiene como referencia esa producción de sentidos, y el derecho a la comunicación está en el centro, y a su vez de manera inseparable al derecho de la salud: las personas tienen no solamente el derecho de expresarse, sino que sus ideas sean consideradas como legítimas, es decir, el derecho de participar en la lucha por otros sentidos en la producción del vivir. 


\section{Reconocerse: construcción de redes y producción de modos de existencia}

La perspectiva relacional considera que se produce sentido no sólo en las instancias de producción y circulación (lo que, simplificando, vendrían a ser el emisor y el canal en la perspectiva instrumental) sino también en el reconocimiento. Así, todos somos no solo productores de sentido, sino que productores y responsables por la circulación de los sentidos, no dejando solamente a las instancias oficiales este proceso, tal como prevé la perspectiva instrumental. Una comunicación multidimensional, entendida como la articulación de prácticas, saberes, memorias, expectativas, emociones, lugares de hablas.

Así, las prácticas de reconocimiento pasan por diferentes instancias y se destacan a partir de las entrevistas: reconocerse a uno mismo como un interlocutor legítimo en el proceso comunicativo y el reconocimiento que adquieren los participantes en otros espacios a partir de ese lugar de comunicadores en una radio.

"Na minha saúde também foi muito bom, porque eu estou há 12 anos no Maluco Beleza e 12 anos sem crises. Por conta disso, sou conselheiro local de saúde e estou me candidatando para ser conselheiro municipal esse ano". (L.3.GF)

Ese reconocimiento está vinculado a una intensa construcción de redes de convivencia y producción de modos de existencia que extrapolan el lugar de la enfermedad mental y del manicomio, como destaca la comunicadora.

"Eles participam das redes sociais. Todos aqui têm facebook e todos se comunicam muito bem ali. Tem pessoas que não sabem nem ler, mas se comunicam muito bem nas redes sociais, tem seus contatos. Inventaram outras formas de comunicação". (C.1.I)

Los participantes no solo ampliaran o bien reforzaron sus redes sociales, sean en espacios virtuales o en movimientos sociales en los cuales están involucrados, como también disputan su propia manera de vivir, produciendo su vida más allá de la enfermedad, como nos cuenta otro locutor en el grupo focal.

"Para mim eu falo e vou dizer de novo. O fato de fazer um programa no rádio e levar para a rede mundial que é a internet significa atuação e crescimento, porque através desse programa eu cresci muito, na maneira de falar, melhorei muito, aprendi. (...) Eu sou portador de deficiência visual, nunca estive atuando em nada, e o fato de eu aparecer, a minha voz para a internet, isso é muito gratificante. Muitas vezes as pessoas podem falar que ele tem uma deficiência, não é capaz de fazer, e com isso ficava escondido, como todos que não faziam isso, antes de ter o Maluco Beleza". (L.4.GF)

Eso significa afirmar que el poder decidir sobre su vida y su cuerpo tiene relación con la idea de reconocerse en el sufrimiento, y éste no prevé necesariamente como única opción el manicomio, los medicamentos o la clínica tradicional. Tener el derecho a producir modos de existencia es reconocerse como una multitud, y que las ofertas para su tratamiento son múltiples también.

\section{Polifonía: el campo y el sujeto con muchas voces}

Según Bakthin (1992), cada habla, enunciado o texto, está expresada una multiplicidad de voces, aunque la mayoría no sea consciente por quien habla. Las 
voces representan distintos intereses y posiciones en la estructura social, hecho que hace con que el lenguaje sea un campo de disputas sociales, en el cual son propuestas, negociadas y ratificadas o rechazadas las relaciones de poder.

Sin embargo, el concepto de polifonía no comprende solamente la posibilidad de muchas voces, sino que implica también entender que cada sujeto es una multiplicidad de voces en disputa, y que a su vez instituye y es instituido por la multiplicidad de voces de los espacios en que vivimos. Por lo anterior, la locura, los manicomios, el loco, el propio sujeto está atravesado por una multiplicidad de voces y discursos. Esa disputa es trabajada en el proceso, como destaca una de las locutoras.

"O que muda, além de tudo isso com a rádio online, é que entra outros coletivos para participar também de toda essa história. $E$ ajuda também a desmitificar a questão do usuário da saúde mental. A comunidade vem, e são crianças, adolescentes em situação de rua, terceira idade. Então entra um misto. É um outro aporte da rádio online". (L.1.I)

Se observa en la entrevistas, como destacamos de lo que nos cuenta la psicóloga, que la posibilidad de producir la comunicación produce a su vez la convivencia en y de la diversidad, es decir, tratando de no desaparecer las diferencias o los ruidos, como prevé la perspectiva informacional de la comunicación.

"Quando a gente quer que a diversidade conviva, a gente não quer que desapareça as diferenças, muito pelo contrário, a gente quer que as diferenças convivam. Esse inclusive é um equívoco que precisa ser superado: eu não sou igual a você, eu sou diferente de você, e o mais legal é que nas nossas diferenças a gente possa fazer coisas interessantíssimas. Esse projeto de comunicação diz disso". (P.1.I)

Con la posibilidad de hacer una gran cantidad de programas, a partir de la radio online, todos los entrevistados cuentan que han ampliado la posibilidad de convivencia de las diferencias, de los distintos temas, de diferentes maneras de hablar, pensar, etc.

\section{Autonomía y Apropiación: ejercicio de libertad}

Dos importantes temas que emergen de la perspectiva relacional de la comunicación aparecen en las entrevistas: autonomía y apropiación. La posibilidad de apropiarse de algo es un parámetro importante para la equidad en la salud, no solamente desde el punto de vista de que la herramienta sea adecuada, sino que se otorgue a las personas la oportunidad de participar en todas las etapas de la comunicación.

Eso ha generado una importante autonomía de los participantes en la producción de los programas, como también ha capturado otros campos de sus vidas, comprendiendo un ejercicio de libertad, entendida aquí como nos presenta Foucault (1995, 2004), es decir, situada en la posibilidad que cada sujeto tiene de definir sus estrategias de cómo vivir, disputando los sentidos sociales vinculados a esas prácticas, como nos cuenta la comunicadora:

"É fantástico receber essa comunicação deles. Eles são muito criativos, muitos são artistas, então eu não preciso produzir nada pronto, de antemão, e dar para eles. Eles têm toda a capacidade do mundo e autonomia para fazer isso. Para que eles se apropriem da comunicação, do espaço que tem aqui disponível. E realmente se tornem comunicadores, por isso eles se apresentam dessa forma, como locutores, como jornalistas". (C.1.I). 
En las entrevistas emerge el tema de la autonomía generada a partir de la participación en la radio, pues no solo son producen todo un programa según sus propias necesidades e intereses, sino que les ha sido proporcionado, por ejemplo, la oportunidad de viajar a encuentros o eventos sin el auxilio de un profesional de la salud. Eso, según se observa en las entrevistas, es un punto muy importante para los participantes, como nos cuenta una de las locutoras:

"Esse crescimento, você poder ir para um lugar como esse, viajar, conhecer outras pessoas, as pessoas te verem de uma forma diferente. É muito importante. Porque como você falou do rótulo da loucura, a autonomia vem para tirar esse rótulo. (...) Essa autonomia de ir, se apresentar, poder falar abertamente, essa questão das palestras. Eu estive em uma universidade e fui representando os usuários da saúde mental, convidada por dois professores, cada um de uma faculdade. São valores mais do que financeiros, isso não tem preço, parodiando a publicidade". (L.1.I)

Esa autonomía ha generado cambios individuales y singulares en los participantes, relacionados con prácticas de cuidado adecuadas a su vida, y no solamente vinculados a discursos preestablecidos en la salud como práctica de cuidado. Ducharse como práctica de higiene, por ejemplo, ha adquirido sentido para uno de los participantes cuando vinculada a la idea de entrevistar a alguien, muy distinto de los discursos higienistas y comportamentales tan arraigados en el campo de la comunicación para la salud.

\section{Diferencia y repetición en el cuidado}

Tener el presupuesto de la comunicación como dispositivo de producción de sentidos, significa también enfrentar una disputa importante en el campo de la salud que es la manera de ver el sufrimiento de las personas como una enfermedad, en un proceso lineal y de repetición que entiende que para hacer frente a ese problema, existen estrategias específicas, científicas, definidas por los profesionales de la salud, para solamente de esa manera llegar a una condición real de salud (Merhy, Feurwerker y Cerqueira, 2010). Una manera lineal de producir la comunicación en el campo de la salud ayuda en ese proceso: para cambiar un comportamiento o práctica no adecuada, hay que dar información a las personas como estrategia (perspectiva informacional). Eso comprende una manera repetitiva de ver el cuidado en salud, sin considerar los más diversos aspectos que comprenden la vida de una persona. Eso podemos observar a partir de lo que nos cuenta la comunicadora:

"Melhora o respeito deles com eles mesmos. Tem também a questão da família respeitá-los pelo que eles são e pelo fazem, eles trazem muito isso. Reconhecem o trabalho deles. Eles não veem a rádio, seja o $\mathrm{MB}$ ou rádio online, como uma diversão. Eles tem um compromisso, no horário, pontual, correto. Eles as vezes quando vão participar de um programa de TV, ficam preocupados com a roupa que vão usar. Esse sentido do cuidado, um respeito com eles próprios. Não só o cuidado relacionado com um diagnóstico de doença mental, é tudo, a parte física (...) A saúde entra no que eles estão fazendo por eles próprios, no bem que fazem a si mesmos". (C.1.I)

Ese modo de hacer la comunicación trabaja con la perspectiva de la diferencia, y permite que emerja y esté en la escena comunicativa los distintos contextos y las diferentes maneras de las personas conducir a su vida. Los entrevistados cuentan, por ejemplo, que hubo mejoras visibles en cuadros psicóticos; la relación de los usuarios 
con sus familias ha mejorado o ha sido restablecida; o bien que la actuación en distintas actividades relacionadas a salud mental - grupo de familiares, luchas por derechos, etc - ha desarrollado una potencia de ayuda mutua, unos a los otros.

Así, la comunicación es entendida como una herramienta de trabajo, es decir, como parte importante de los proyectos de cuidado, como nos cuenta el siguiente locutor:

"Eu já estou praticamente há 12 anos na rádio MB e para minha saúde me ajudou muito. São 12 anos sem crise. As vezes eu ainda tenho algumas alucinações, mas eu consigo superar e a rádio tem me ajudado bastante". (L.2.I)

Los psiquiatras de la institución, por ejemplo, "prescriben" la participación en la radio como una alternativa positiva en los tratamientos como nos relata una de las locutoras:

"Os próprios psiquiatras falam para os usuários sobre a rádio, perguntam se conhecem, se já estiveram por lá. Eles recomendam. Eles sabem como funciona. Eles entram com medicamentos, aquela coisa certinha, acompanhamento e agente entra com a parte legal da coisa. Eles incentivam. A melhora das pessoas que passam por aqui ou frequentam aqui é muito grande. (...) Aqui ninguém precisar saber o CID [Classificação Internacional de Doenças] de ninguém. Isso não é o principal, o diagnostico não nos importa". (L.1.I)

Sin excepción, todos cuentan historias de mejoras, de superación, y afirman: eso es salud.

"Aqui só tem coisas positivas, e coisas positivas só tendem a nos ajudar". (L.5.GF)

\section{Conclusiones}

La comunicación para la salud es un campo en desarrollo en Brasil, donde coexisten una disputa de esos modelos y concepciones, muchas veces antagónicos, al combinar la práctica y la teoría. Por un lado, nos damos cuenta de la resistencia que impone los modelos hegemónicos y los obstáculos para un verdadero cambio en las prácticas comunicativas. Por otra parte, se observa la evidencia de la vitalidad de la sociedad y sus diferentes formas de producción de la realidad (Araújo y Cardoso, 2007).

Uno de los cambios más profundos de la perspectiva relacional viene dado por considerar que se produce sentido no sólo en las instancias de producción y circulación (lo que, simplificando, vendrían a ser el emisor y el canal en la perspectiva instrumental) sino también en la de reconocimiento, como se ha podido comprobar en el caso de estudio presentado.

Los procesos comunicativos en el campo de la salud, como en el proyecto "Maluco Beleza", deben buscar articular en todas las etapas los saberes y miradas de los diversos actores que participan en el proceso de salud, trabajadores y usuarios, considerando las realidades y particularidades de cada uno, los vínculos y mediaciones existentes en cada comunidad para de esta manera trabajar las problemáticas de la salud y promover la participación de las personas, individual y colectivamente, en los procesos que dicen respecto a su salud y a su vida. 
El proyecto proporciona a las personas involucradas un proceso de educación e inclusión social a través del trabajo en la radio. Es un espacio de construcción de dialogo en el cual se promueve la participación, siendo el referente de las acciones y programas las necesidades de los usuarios y trabajadores del local, contribuyendo con los procesos de participación en la mejora del cuidado en salud. La interpretación de los usuarios de salud sobre los fatos del cotidiano, incluso su enfermedad, es una producción de saberes que no son contempladas en el espacio hegemónico de los medios de comunicación, los cuales privilegian el discurso científico oficial. La comunicación y salud, de esa manera, pueden encontrarse tanto en la producción de saberes, cuanto en el cotidiano de los servicios (Oliveira Neto y Pinheiro, 2013).

En la perspectiva relacional, se comprende que todas las personas tienen gran cantidad de informaciones y saberes que se articulan, hecho que implica afirmar que no existe la pretensión de transferir mensajes a un receptor carente de referencias. EI receptor, en esta perspectiva, es un interlocutor, un co-productor de sentidos que se constituye en el acto interlocutorio. Somos todos no solo productores de sentidos, sino que productores y responsables por la circulación de los sentidos, no dejando solamente a las instancias oficiales este proceso, tal como prevé la perspectiva instrumental.

La comunicación para la salud dentro de este razonamiento, en lugar de valorar solamente a los discursos tradicionalmente autorizados, tales como las instituciones y servicios/equipos de salud, fomenta la participación y reconoce la existencia de la polifonía social, de la capacidad de acoger y amplificar las muchas voces que contienen cantidad de significados posibles para la salud, marcada no solamente por la ausencia de enfermedades. Es también una comunicación que entiende que el conocimiento sobre la salud no se produce solamente a partir de los conocimientos técnicos y científicos, sino que se da a través de la articulación de un conjunto de prácticas, conocimientos, recuerdos, expectativas, emociones, etc., constituidos por las voces que emanan de todos los actores implicados en el proceso de salud: las instituciones, los trabajadores y la población. 


\section{Referencias}

Araújo, Inesita Soares de y Cardoso, Janine Miranda (2007). Comunicação e Saúde. Rio de Janeiro: Editora Fiocruz.

Bakhtin, Mikhail (1992). Marxismo e Filosofia da Linguagem. São Paulo: Hucitec.

Brasil (2005). PARTICIPASUS - Política Nacional de Gestão Participativa para o SUS. Brasília: Ministério da Saúde.

CEPAL (2003). Los caminos hacia una sociedad de la información en América Latina y el Caribe. Conferencia Ministerial Regional Preparatoria de América Latina y el Caribe para la Cumbre Mundial sobre la Sociedad de la Información. (Bávaro, Punta Cana, República Dominicana, 29 al 31 enero, 2003).

Cisterna, Francisco Cabrera (2005). "Categorización y triangulación como procesos de validación del conocimiento en investigación cualitativa". Theoria, año/vol. 14, número 001, pp. 61-71. Chile: Universidad del Bío-Bío.

Conde, Fernando y Pérez Andrés, Cristina (1995). "La investigación cualitativa en salud pública”. Rev Esp Salud Pública, 69, n. 2, pp. 145-149, Marzo-Abril.

Díaz, Hernán Alfredo (2011). "La Comunicación para la salud desde una perspectiva relacional". En: Cuesta Cambra, Ubaldo; Menéndez Hevia, Tania y Ugarte Iturrizaga, Aitor (2011). Comunicación y salud: Nuevos escenarios y tendencias. Madrid: Editorial Complutense.

Díaz, Hernán y Uranga, Washington (2011). "Comunicación para la salud en clave cultural y comunitaria". Revista de Comunicación y Salud. Vol.1, no 1, pp. 113-124.

Merhy, Emerson Elias; Feurwerker, Laura Camargo Macruz y Cerqueira, Maria Paula (2010). "Da repetição à diferença: construindo sentidos com o outro no mundo do cuidado". En Ramos, VC. Semiótica, afecção \& cuidado em saúde. São Paulo: Hucitec, p. 60-75.

Minayo, Maria Cecília de Souza (1992).O desafio do conhecimento. Pesquisa Qualitativa em Saúde. São Paulo: Hucitec.

Oliveira Neto, Alfredo y Pinheiro, Roseni (2013). "O que a saúde tem a ver com rádio comunitária? Uma análise de uma experiência em Nova Friburgo - RJ". Ciência \& Saúde Coletiva, n. 18(2), pp. 527-536.

Salvat, Guiomar y Serrano, Vicente (2011). La revolución digital y la Sociedad de la Información. Zamora: Comunicación Social. 